Article

\title{
Preliminary Characterization of Yeasts from Bombino Bianco, a Grape Variety of Apulian Region, and Selection of an Isolate as a Potential Starter
}

\author{
Barbara Speranza, Daniela Campaniello, Leonardo Petruzzi, Milena Sinigaglia, \\ Maria Rosaria Corbo and Antonio Bevilacqua * \\ Department of the Science of Agriculture, Food and Environment, University of Foggia, Via Napoli 25, 71121 \\ Foggia, Italy; barbara.speranza@unifg.it (B.S.); daniela.campaniello@unifg.it (D.C.); \\ leonardo.petruzzi@unifg.it (L.P.); milena.sinigaglia@unifg.it (M.S.); mariarosaria.corbo@unifg.it (M.R.C.) \\ * Correspondence: antonio.bevilacqua@unifg.it
}

Received: 6 November 2019; Accepted: 12 December 2019; Published: 15 December 2019

\begin{abstract}
Eighty-seven yeasts were isolated from Bombino bianco, a white grape variety from Apulian Region (Southern Italy). The isolates were characterized for the splitting of arbutin, the hydrolysis of pectins, sulphite production, the resistance to acetic acid, $\mathrm{SO}_{2}$, and ethanol. An enhanced arbutin splitting ( $\beta$-glucosidase) and a moderate pectolytic activity were found. Concerning ethanol resistance, the most of yeast population showed a low-to-moderate resistance, but some isolates, identified as Saccharomyces cerevisiae, were able to grow in presence of $15 \% v / v$ of ethanol. Four isolates were selected (coded as 43D, 44D, 45D, and 46D), studied for their ability to decarboxylate amino acids and used in small-scale fermentation trial; for this last experiment a reference strain was used (S. cerevisiae EC1118). This experiment suggested the existence of an isolate (S. cerevisiae 46D) with interesting traits and performances, which could be potentially proposed as a starter for Bombino bianco.
\end{abstract}

Keywords: yeasts; Bombino bianco; technological characterization; enzymatic patterns; amino acid decarboxylation

\section{Introduction}

Apulia (Southern Italy) is the second Italian area for wine production. The Apulian wines detain several peculiarities because of pedologic features, climatic conditions, and technologies, all contributing to the definition of a unique "terroir" [1]. Among the innovative trends in the wine sector, the continuous exploration of oenological properties associated with wine microbial resources represents a cornerstone driver of quality improvement [2]. Autochthonous starter cultures have a potential important role on wine quality because of their key-role on organoleptic properties [3].

Yeast strains involved in winemaking influence fermentation speed, nature and quantity of secondary products, and aromatic characters of wine [4]. Yeast microbiota generally comprise oxidative yeasts, which belong to the genera Rhodotorula, and Hanseniaspora. They comprise up to the $99 \%$ of the yeasts isolated in certain grape samples [5]. Other yeasts usually found on grape are Metschnikowia pulcherrima, Candida famata, Candida stellata, Pichia membranifaciens, Pichia fermentans, Hansenula anomala, and, in small proportions, Saccharomyces spp. [5].

Many researchers focused on the oenological performances of indigenous yeasts isolated from red Apulian grapes, must, and spontaneous fermentation from Primitivo [6], Negroamaro [7], Uva di Troia [8,9], and Susumaniello, an ancient and recently rediscovered grape cultivar [10]. However, to the best of our knowledge, little is known on yeast microbiota of Bombino bianco. Vitis vinifera $\mathrm{L}$. Bombino bianco is a cultivar widespread since ancient times in the Apulia region where is present with 
a surface of 2000 ha, mainly located in Foggia and Bari counties [11]. This variety can be also found in other regions of Southern Italy, where it is usually referred as Bonvino, Ottenese, Trebbiano d'oro, Trebbiano d'Abruzzo, Uva d'Oro, or Gold Trauben. The main traits are a high yield, a good resistance to bad weather conditions as well as to grape diseases, such as Plasmopara or Botrytis [12]. Bombino bianco grapes are typically blended with grapes of other varieties for the production of many DOC and IGT wines, but they can be also used alone to produce sparkling wines through the Champenoise method [13].

This paper represents a first approach for the evaluation of yeast diversity and characteristics on Bombino bianco grapes, with a special focus on enzymatic patterns, technological characteristics and safety issues (amino acid decarboxylation), as a prodromal to select and design a wild starter culture for this grape variety.

\section{Materials and Methods}

\subsection{Yeast Isolation}

Wine grapes (Vitis vinifera L.; Bombino bianco variety) were harvested from a local farm in the Apulian region (Foggia, Italy). Skin and inner part were analyzed. For skins, the sample was treated as follows: $25 \mathrm{~g}$ of grapes were detached from different clusters, immersed in $225 \mathrm{~mL}$ sterile isotonic solution $(0.9 \% \mathrm{NaCl})$ and shaken for $30 \mathrm{~min}$ at $200 \mathrm{rpm}$. For the inner part, $25 \mathrm{~g}$ of grapes were diluted in $225 \mathrm{~mL}$ sterile isotonic solution $(0.9 \% \mathrm{NaCl})$ and homogenized through a steril-mixer. The serial dilutions of homogenates (skin and inner part) were spread onto appropriate media and incubated at $25^{\circ} \mathrm{C}$ for $48 \mathrm{~h}$. The media were the following: Sabouraud Dextrose Agar (Oxoid, Milan, Italy); YPG Agar (bacteriological peptone $20 \mathrm{~g} / \mathrm{L}$, yeast extract $10 \mathrm{~g} / \mathrm{L}$, glucose $20 \mathrm{~g} / \mathrm{L}$, agar $15 \mathrm{~g} / \mathrm{L}$; ingredients were purchased from Oxoid); YM Agar (bacteriological peptone $5 \mathrm{~g} / \mathrm{L}$, malt extract $3 \mathrm{~g} / \mathrm{L}$, yeast extract $3 \mathrm{~g} / \mathrm{L}$, dextrose $10 \mathrm{~g} / \mathrm{L}$, agar $15 \mathrm{~g} / \mathrm{L}$; ingredients were purchased from Oxoid); WL Nutrient Agar (Oxoid). All media were supplemented with $0.1 \mathrm{~g} / \mathrm{L}$ of chloramphenicol (C. Erba, Milan, Italy).

From each plate and at each time of analysis, 5 colonies were randomly selected, isolated and stored on YPG Agar at $4{ }^{\circ} \mathrm{C}$ until the identification; a preliminary characterization between Saccharomyces and non-Saccharomyces yeasts was done by streaking the isolates on WL medium.

\subsection{Arbutin Splitting Test}

$\beta$-D-glucosidase activity was evaluated by using the arbutin splitting test. YNB-Agar (Yeast Nitrogen Base, Oxoid), supplemented with $0.5 \%$ arbutin (Sigma-Aldrich, Milan, Italy) and $2 \%$ ferric ammonium citrate (J.T. Baker, Milan, Italy) solution, was used [14]. The plates were incubated at $26^{\circ} \mathrm{C}$ for 2 to 4 days. The outcome of the experiment was evaluated by means of color change to brown. A qualitative code was used to classify the results as follows: no activity (no halo, - ); weak activity (diameter of the halo $<17 \mathrm{~mm},+$ ); medium/strong activity (diameter of the halo $>18 \mathrm{~mm},++$ ) [15].

\subsection{Hydrolysis of Pectins}

The extracellular pectolytic activity was assessed by measuring the growth zones of yeasts on YM Agar, without glucose and supplemented with $12.5 \mathrm{~g} / \mathrm{L}$ of apple pectins (Sigma-Aldrich) and adjusted to $\mathrm{pH} 4.0$ with $\mathrm{HCl} 1.0 \mathrm{~N}$. The plates were incubated at $25^{\circ} \mathrm{C}$ for 10 days [16]. The outcome of the experiment was evaluated as a function of the diameter of the growth zone, as reported by Hernández et al. [17]: the activity was classified as weak $(+)$, when the growth zone was $<5.5 \mathrm{~mm}$ or strong $(++)$, when the growth zone was $>5.5 \mathrm{~mm}$.

\subsection{Sulphite Production}

The test was done on BiGGY Agar medium (Oxoid), as reported by Barbosa et al. [13]. After yeast inoculation, the plates were incubated for $2-4$ days at $26^{\circ} \mathrm{C}$. The different intensity of the color of 
colonies (from white to heavy brown) was used to evaluate the quantitative outcome of the test (white, no production of $\mathrm{H}_{2} \mathrm{~S}$; cream, weak production; light and dark brown, medium-to-high production) [15].

\subsection{Resistance to Acetic Acid, Ethanol and $\mathrm{SO}_{2}$}

The tests were performed by using YPG Agar, supplemented with 3\%, 6\%, 9\%, $12 \%$, and $15 \%(v / v)$ ethanol (C. Erba, Milan, Italy), $0.05 \%, 0.1 \%, 0.15 \%, 0.20 \%, 0.25 \%$, or $0.3 \%$ acetic acid, and 50,100 and $150 \mathrm{mg} / \mathrm{L} \mathrm{SO}_{2}$. After streaking the strains onto the surface of the medium, the plates were incubated at $25^{\circ} \mathrm{C}$ for 7 days.

\subsection{Preliminary Identification}

Some selected isolates were identified as reported by Sinigaglia et al. [18].

\subsection{Amino Acid Decarboxylation}

Yeasts were streaked onto the surface of a laboratory medium containing amino acids as precursors of amines and a $\mathrm{pH}$ indicator (bromocresol purple): an increase of $\mathrm{pH}$ due to decarboxylation of amino acids causes a color turning from green to purple. The composition of the medium, modified from a substrate proposed by Bover-Cid and Holzapfel [19] for lactic acid bacteria, was the following: bacteriological peptone, $5 \mathrm{~g} / \mathrm{L}$; yeast extract, $5 \mathrm{~g} / \mathrm{L}$; glucose, $1 \mathrm{~g} / \mathrm{L} ;$ amino acid, $10 \mathrm{~g} / \mathrm{L}$; agar, $12 \mathrm{~g} / \mathrm{L}$; bromocresol purple, $0.06 \mathrm{~g} / \mathrm{L}$ (Sigma-Aldrich); pyridoxal-5-phosphate hydrate (Sigma-Aldrich), $0.05 \mathrm{~g} / \mathrm{L}$. The $\mathrm{pH}$ of the medium was adjusted to 5.2. Arginine hydrochloride, cysteine, L-histidine, L-tyrosine, L-phenlalanine, serine, gliycine, L-proline, and L-lysine (Sigma-Aldrich) were used; after yeast inoculation, the plates were incubated at $25^{\circ} \mathrm{C}$ for $72 \mathrm{~h}$ and checked every day. Laboratory media without amino acids but inoculated with yeasts were used as controls.

\subsection{Lab-Scale Fermentations and Confirmation of the Technological Performances}

The assays were done only for the isolates 43D, 44D, 45D, and 46D; the strain S. cerevisiae EC1118 (Lallemand Inc., Castel D'Azzano, VR, Italy) was used as reference. The first experiment was a confirmation of the technological performances in a model medium, as reported by Petruzzi et al. [15]. A synthetic medium was prepared as follows: $100 \mathrm{~g} / \mathrm{L}$ of glucose; $100 \mathrm{~g} / \mathrm{L}$ of fructose (Sigma-Aldrich, Milan, Italy); $10 \mathrm{~g} / \mathrm{L}$ of yeast extract; $1 \mathrm{~g} / \mathrm{L}$ of 21 ammonium sulfate (J. T. Baker, Milan, Italy); $1 \mathrm{~g} / \mathrm{L}$ of potassium phosphate (C. Erba); and $1 \mathrm{~g} / \mathrm{L}$ of magnesium sulfate (J. T. Baker).

Flasks of $150 \mathrm{~mL}$, containing $100 \mathrm{~mL}$ of medium, were used for the experiments. After sterilization, citric acid $(10 \mathrm{~g} / \mathrm{L})$ was added to the medium to decrease the $\mathrm{pH}$ to 3.5 ; then the medium was inoculated with yeasts (ca. $6 \log \mathrm{cfu} / \mathrm{mL}$ ), and the surface was covered with a thin layer of sterilized paraffin oil (10 mL per flask) in order to avoid air contact. The samples were incubated at $25^{\circ} \mathrm{C}$ without shaking. Residual sugars, ethanol, glycerol, and volatile acidity were determined by Fourier transform infrared spectroscopy using a WineScan FT120 instrument (software version 2.2.1, FOSS Analytical, Hillerød, Denmark) according to the supplier's instructions.

A second experiment was done in a real must. The fermentation was carried out in duplicate on two independent batches in $250 \mathrm{~mL}$ Erlenmeyer flasks containing $150 \mathrm{~mL}$ of pasteurized Bombino bianco must (sugar content, $15.75 \pm 0.17^{\circ} \mathrm{Bx}$; titrable acidity, $4.09 \pm 0.53 \mathrm{~g}$ of tartaric acid; $\mathrm{pH}$, $3.76 \pm 0.08$ ). Yeasts were grown in YPG broth at $25{ }^{\circ} \mathrm{C}$ for $72 \mathrm{~h}$, centrifuged at $4{ }^{\circ} \mathrm{C}$ for $10 \mathrm{~min}$ at $1200 \times g$ and suspended in distilled water. The inocula represented $1 \%$ of the total fermentation volume of flasks.

The flasks were stoppered with cotton plugs to allow the $\mathrm{CO}_{2}$ to escape from the system, and the weight loss of the flasks due to $\mathrm{CO}_{2}$ production was evaluated every day, until the end of fermentation (constant weight for three consecutive days). The fermentations were carried out under static conditions at $25{ }^{\circ} \mathrm{C}$ on two independent batches; weight loss and cell viability (YPG agar plates, incubated at $25^{\circ} \mathrm{C}$ for 4 days) were assessed. 


\subsection{Statistic}

The phenotypic tests were performed in triplicate; the results were plotted as frequency histograms. The outcome of the qualitative test was assessed as positive, if at least 2 replicates were positive. For the quantitative assays (pectin hydrolysis), for each isolate the average of the growth zone was evaluated.

The results of the analytical determinations in the synthetic must were analyzed by means of one-way analysis of variance and Tukey's test $(p<0.05)$.

The data of weight loss were modelled as weight loss ( $\mathrm{mg} \mathrm{CO} \mathrm{CO}_{2}$ per $\mathrm{ml}$ of must) through the lag-exponential model by van Gerwen and Zwietering [20] and by Baty and Delignette-Muller [21], cast in the following form:

$$
\mathrm{Y}=\left\{\begin{array}{cc}
0 & t \leq \alpha \\
y_{\max }-\log \left\{1+\left(10^{\mathrm{ymax}}-1\right) \times \exp \left[-d_{\max }(t-\alpha)\right]\right\} & t>\alpha
\end{array} .\right.
$$

where: $y$ and $t$ are the dependent and independent variables, respectively (weight loss and time-day); $\alpha$ is the time before the beginning of the fermentation (day); $d_{\max }$ is the maximal fermentation rate; $\mathrm{y}_{\max }$ is the maximum level of weight loss.

When the kinetic did not show the parameter $\alpha$, the lag-exponential model was used as follows [22]:

$$
y=y_{\max }-\log \left\{1+\left(10^{\text {max }}-1\right) \times \exp \left(-d_{\max } t\right)\right\}
$$

Statistic was performed through the software Statistica for Windows ver. 12.0 (Statsoft, Tulsa, Oklha).

\section{Results}

As a result of yeast selection, 87 isolates were recovered; 44 showed a green color on WL medium (non-Saccharomyces), and 43 were yellow. Figure 1 shows the results for the preliminary phenotyping (arbutin splitting, sulphite production, and pectolytic activity). Focusing on $\beta$-glucosidase activity (arbutin splitting), 68 strains could perform the splitting of the arbutin; for 43 isolates this ability was low-to-moderate (weak response) and for 25 isolates strong. Only 19 isolates were negative to the splitting of the arbutin, all of them belonging to non-Saccharomyces yeasts.

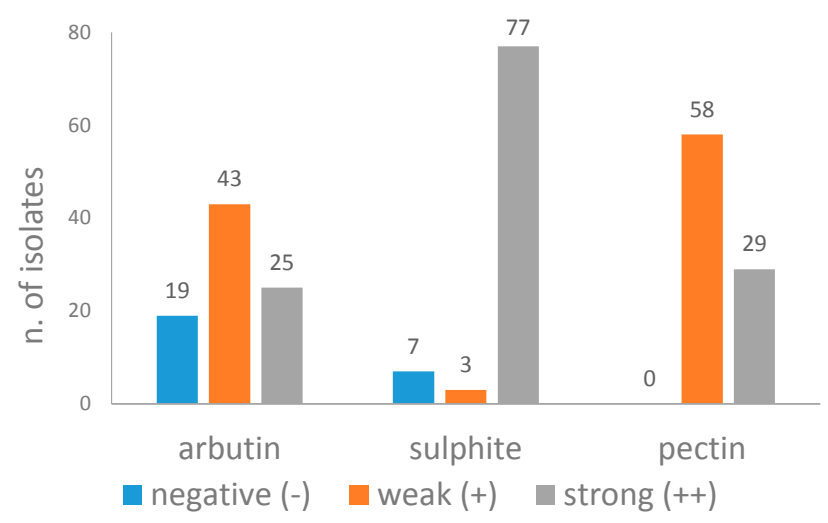

Figure 1. Arbutin splitting, sulphite production, and pectolytic activity. The numbers on the bars represent the number of isolates per each class (for the details on the classification see Materials and Methods).

The production of $\mathrm{H}_{2} \mathrm{~S}$ is a negative property for its strong impact on the sensorial quality of wine. Yeasts isolated from Bombino Bianco possessed this ability and 77 isolates (ca. 90\% of the population) expressed this ability at the highest level $(++)$; otherwise for three isolates this kind 
of metabolism appeared moderate (yellow colonies on WL), and only seven isolates were negative (non-Saccharomyces).

Another trait assessed was the pectolytic activity, recovered in all isolates from a weak response (58 yeasts) to a strong one (29 isolates).

Isolates were also studied in relation to resistance to acetic acid, ethanol, and $\mathrm{SO}_{2}$. Concerning the resistance to acetic acid, all isolates were able to grow till a maximum concentration of $0.10 \%$. The results for ethanol resistance are reported in Figure 2, as number of yeasts able to grow for each ethanol amount; 76 isolates were able to grow in presence of $3 \%$ ethanol, while only 13 were able to grow at $15 \% . \mathrm{SO}_{2}$ exerted a strong impact on yeasts and only four isolates were able to grow in the medium containing 150 ppm of this compound (Figure 3).

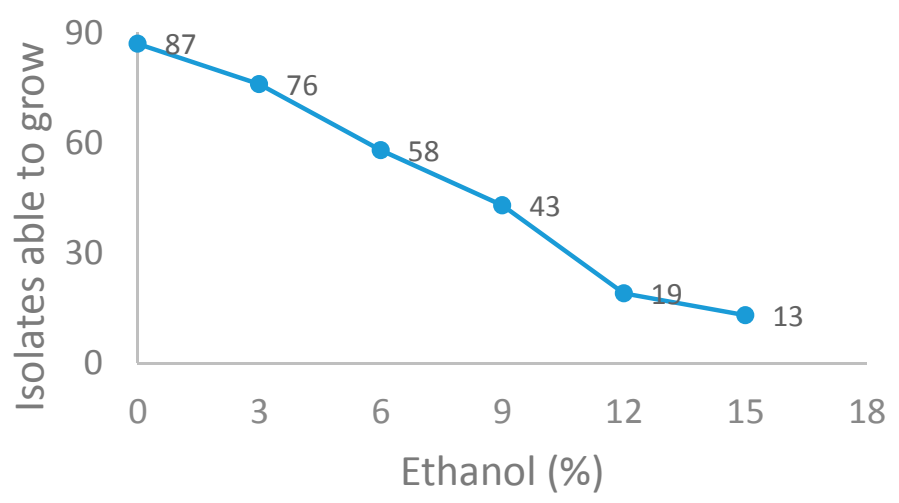

Figure 2. Growth of yeasts on lab media containing ethanol. The results are expressed as number of isolates able (positive) to grow for each ethanol amount.

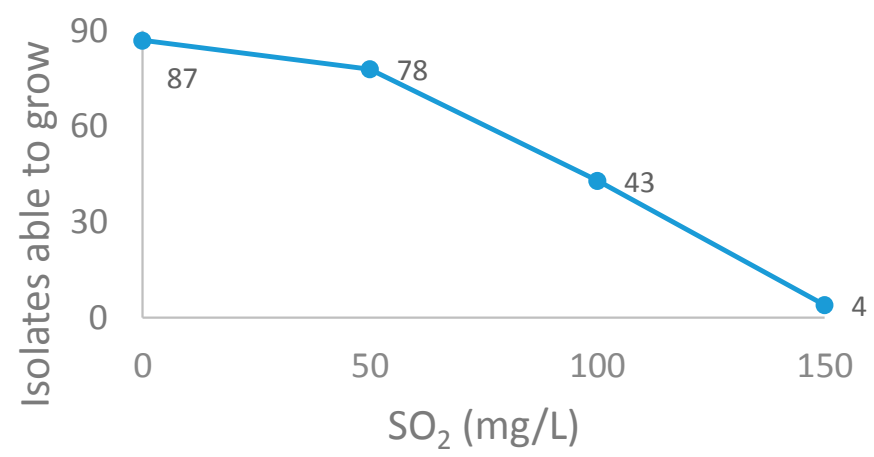

Figure 3. Growth of yeast isolates on lab media $\mathrm{SO}_{2}$. The results are expressed as number of isolates (positive) able to grow for each amount of $\mathrm{SO}_{2}$.

By using phenotyping, a selection of isolates for the second step was done; ethanol and $\mathrm{SO}_{2}$ tolerance were used as primary criteria and only yeasts able to grow in media containing $15 \%$ ethanol and $150 \mathrm{ppm}$ of $\mathrm{SO}_{2}$ were selected. Thus, four isolates were used for the second step $(43 \mathrm{D}, 44 \mathrm{D}, 45 \mathrm{D}$, and 46D); they all possessed a moderate arbutin splitting, a strong pectolytic activity, while sulphite production was negative for the isolates 43D and 44D and weak for the isolates 45D and 46D (Table 1). 
Table 1. Enzymatic activities of selected isolates. Cat, catalase; Arb, arbutin splitting; Sul, sulphite production; Pec, pectolytic activity; $\mathrm{SO}_{2}$, resistance to $\mathrm{SO}_{2} ; \mathrm{EtOH}$, resistance to ethanol; Acetic, resistance to acetic acid. - , negative; + , moderate; ++ , strong.

\begin{tabular}{cccccccc}
\hline Yeast Isolates & Cat & Arb & Sul & Pec & SO $_{2}$ & EtOH & Acetic \\
\hline $43 \mathrm{D}$ & ++ & + & - & ++ & $\begin{array}{c}150 \\
\text { ppm }\end{array}$ & $15 \%$ & $0.10 \%$ \\
$44 \mathrm{D}$ & ++ & + & - & ++ & $\begin{array}{c}150 \\
\mathrm{ppm}\end{array}$ & $15 \%$ & $0.10 \%$ \\
$45 \mathrm{D}$ & + & + & + & ++ & $\begin{array}{c}150 \\
\mathrm{ppm}\end{array}$ & $15 \%$ & $0.10 \%$ \\
$46 \mathrm{D}$ & + & + & + & ++ & $\begin{array}{c}150 \\
\mathrm{ppm}\end{array}$ & $15 \%$ & $0.10 \%$ \\
\hline
\end{tabular}

These isolates were identified as S. cerevisiae and studied for the decarboxylation of amino acids; Table 2 shows the data of decarboxylation. The isolates 43D, 44D, and 45D were negative, whilst the isolate $46 \mathrm{D}$ was positive to the decarboxylation of arginine, lysine, and tyrosine.

Table 2. Results for the test on the decarboxylation activity. A, arginine; B, cysteine; $\mathrm{C}$, phenylalanine; $\mathrm{D}$, glycine; $\mathrm{E}$, histidine; $\mathrm{F}$, lysine; $\mathrm{G}$, proline; $\mathrm{H}$, serine; I, tyrosine. -, negative; + , positive to the assay; $+/-$, variable.

\begin{tabular}{cccccccccc}
\hline Yeast Isolates & A & B & C & D & E & F & G & H & I \\
\hline $43 \mathrm{D}$ & - & - & - & - & - & - & - & - & - \\
$44 \mathrm{D}$ & - & - & - & - & - & - & - & - & - \\
$45 \mathrm{D}$ & - & - & - & - & - & - & - & - & - \\
$46 \mathrm{D}$ & + & - & - & - & - & $+/-$ & - & - & + \\
\hline
\end{tabular}

The last experiments focused on the assessment of the technological performances through a small-scale fermentation trials; the strain EC1118 was used as a reference. A first assay was done in a synthetic medium for the evaluation of some target compounds (ethanol, glycerol, and volatile acidity). The isolates showed similar traits, and produced $8.78-11.20 \mathrm{~g} / \mathrm{L}$ of ethanol, 5.45-6.21 g/L of glycerol and $0.36-0.45 \mathrm{~g} / \mathrm{L}$ of acetic acid; sugar was always $<2 \mathrm{~g} / \mathrm{L}$. The differences were not significant (Table 3).

Table 3. Technological performances. Ethanol, glycerol, and acetic acid produced in a synthetic medium.

\begin{tabular}{cccc}
\hline Yeast Isolates & Ethanol $(\mathrm{g} / \mathrm{L})$ & Glycerol $(\mathrm{g} / \mathrm{L})$ & $\begin{array}{c}\text { Volatile Acidity } \\
\text { (Acetic Acid, } \mathbf{g} / \mathrm{L})\end{array}$ \\
\hline 43D & $9.76 \pm 0.98$ & $5.64 \pm 0.89$ & $0.45 \pm 0.09$ \\
44D & $8.78 \pm 1.21$ & $5.45 \pm 0.63$ & $0.36 \pm 0.12$ \\
45D & $9.89 \pm 0.06$ & $6.12 \pm 0.65$ & $0.41 \pm 0.07$ \\
46D & $10.25 \pm 0.34$ & $6.21 \pm 0.09$ & $0.42 \pm 0.08$ \\
Ec1118 & $11.20 \pm 0.43$ & $6.01 \pm 0.11$ & $0.39 \pm 0.12$ \\
\hline
\end{tabular}

In a second experiment, the fermentation kinetic in a Bombino bianco must was studied; Figure 4 shows the results as standardized weight loss (mg of $\mathrm{CO}_{2}$ per $\mathrm{mL}$ of must).

The kinetic followed a logistic-like model; however, two different trends were recovered-the first one for the isolates 43D and 44D, and the second one for the isolates 45D, 46D, and the reference strains. The isolates 43D and 44D experienced a logistic-like trend with a lag phase (parameter $\alpha$ ), where no weight loss occurred; the duration of this period was 4.40 days for the isolate $43 \mathrm{D}$ and 2.30 day for the isolate $44 \mathrm{D}$. On the other hand, the isolate 45 and 46D showed the same trend of the reference strain and the fermentation started immediately after the inoculation and no lag phase was found. All isolates experienced a similar maximum weight loss (ca. $55 \mathrm{mg}$ of $\mathrm{CO}_{2}$ per mL of must) and fermentation rate (18-20 $\mathrm{mg}$ of $\mathrm{CO}_{2}$ per $\mathrm{ml}$ of must and per day). 


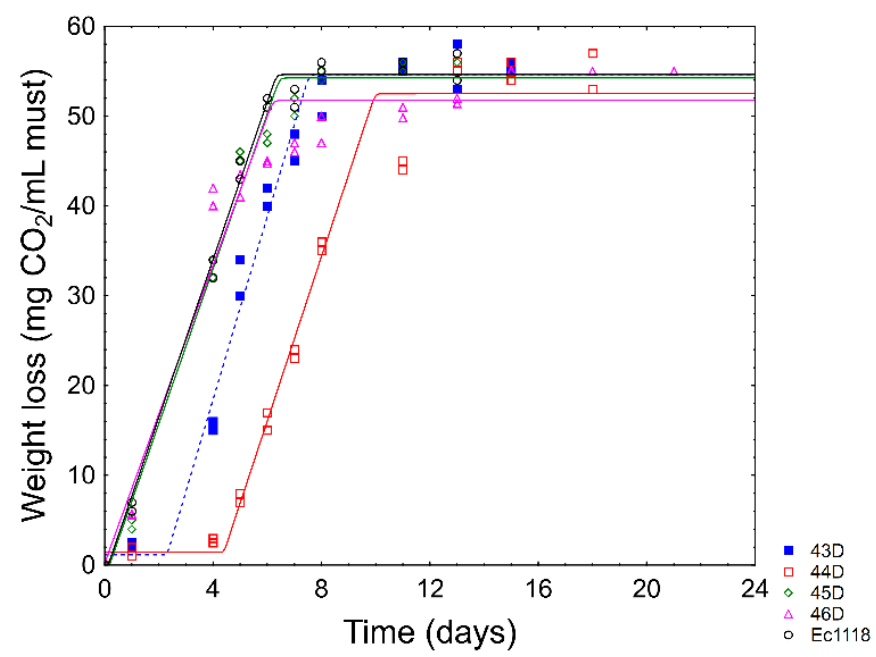

Figure 4. Fermentation kinetics of isolates 43D, 44D, 44D, and 45D compared to S. cerevisiae EC1118; the lines represent the best fit through the lag-exponential model.

\section{Discussion}

The selection of a starter is a complex process, as it involves different steps; however, the interest towards wild strains and the selection of potential starter microorganisms from the natural occurring microflora of many foods increased, as it is well known that autochthonous microorganisms could contribute to quality and safety of final products. Concerning yeasts for oenological use, we focused on a traditional grape variety of Apulian region (Bombino bianco) and performed the first steps of strain selection. Some varieties of Apulian region were studied for the qualitative composition of yeast microbiota [8-10,23]; to the best of our knowledge, little is known on Bombino bianco. After strain isolation, we characterized yeasts for some enzymatic activities ( $\beta$-glucosidases, hydrolysis of pectins, sulphite production) and technological properties (ethanol tolerance, resistance to acetic acid). Concerning $\beta$-glucosidase, the potential applications of this enzyme include the prevention of sediments in the bottles during storage, as well as the production of volatile compounds [24]. Research on $\beta$-glucosidase in yeasts has revealed that most Saccharomyces isolates do not show activity in a natural substrate and that such activity is more frequent in non-Saccharomyces strains [25], from a weak to a strong activity as reported by Fia et al. [26] for some strains belonging to Brettanomyces, Metschnikowia spp. and Hanseniaspora genera. However, some authors found in the past $[9,27,28]$ that Saccharomyces strains also possessed this activity. The recovery of some isolates able to perform arbutin splitting is a promising result, for the implication of this metabolism in wine flavour and taste. Concerning sulphite production, this trait is unfavorable, because it is related to the production of off-flavours and off-odours; however, it is well known that this metabolic activity is common amongst wine yeasts [17] and Mendes-Ferreira et al. [29] also reported that production could be strongly affected by the physiological conditions of yeasts. Therefore, strain selection would focus on the choice of low-producer strains.

The impact of pectolytic activity is different in relation to yeast use and destination; therefore, in fermented vegetables, above all in table olives, this activity is negative as it could contribute to olive softening and spoilage [30]. Otherwise, its role in wine is not clear; many authors consider this ability not relevant [17], but in some cases, it is a common idea that it could be useful (for example to produce cider). Pectinolytic enzymes are polysaccharidases that degrade pectins present in middle lamella and primary cell walls of plants; this ability is widely used in winemaking as pectinases can help to improve liquefaction, juice yield, clarification, filterability, and to increase the release of color and flavor compounds entrapped in grape skins. Although this trait was found in some isolates of Aureobasidium pullulans, Hanseniaspora sp., Metschnikowia sp. [31], some experiments done in the past 
with $S$. cerevisiae strains from a red grape variety (Uva di Troia) suggest that also isolates from this species could possess this trait [9].

We also focused on some technological traits of wine yeasts (tolerance to ethanol and resistance to acetic acid); the results were generally in line with the literature, and only few isolates tolerated up to $15 \%$ of ethanol.

After the study of some phenotypic traits, a preliminary selection was done based on two criteria (ability to grow in presence of $15 \%$ ethanol and 150 ppm of $\mathrm{SO}_{2}$ ). As expected, these criteria were strongly restrictive only four isolates were selected; the genotyping confirmed their attribution to the species $S$. cerevisiae.

The last trait assessed for the technological characterization was the evaluation of the decarboxylation of amino acids, as this this is the major pathway for the synthesis of biogenic amines. The production of biogenic amines is of concern, because EFSA and other Regulatory Agencies require that strains for human use must not possess toxicogenic activity and/or negative effect on health [32]. The results of this assay confirm the possibility of recovering this trait in yeast microbiota, as reported by other authors [23,33]; it poses some safety issues for the selection of starter cultures from the wild microbiota, as biogenic amines could have deleterious effects on the well-being. Moreover, it also stressed that interesting microorganism (like the isolate $46 \mathrm{D}$, with high ethanol and $\mathrm{SO}_{2}$ tolerance) could exhibit this property.

The last assay was a small-scale fermentation with the selected isolates and a reference strain was added (EC1118); the isolates 45D and 46D showed fermentative performances like the reference strain (high fermentation rate, significant weight loss). The other two isolates (43D and 44D) experienced a variable time (from two to four days) before the beginning of the fermentation. In a primary fermentation this trend could be a problem, as the lack of ethanol in the first days could induce the growth of a competitive microbiota. The technological traits in terms of ethanol, acetic acid, and glycerol produced were in line with the data recovered for some isolates from grape varieties of Sourthern Italy $[1,3,15]$.

Therefore, as a final selection only the isolate $45 \mathrm{D}$ could be proposed as a potential starter for Bombino bianco, because of its phenotypic traits (fermentative trend similar to a refence strain, glucosidase activity, high resistance to ethanol), while the other three isolates should be excluded for the potential production of biogenic amines (46D) or for the presence of a lag phase before the beginning of fermentation (isolates $43 \mathrm{D}$ and $44 \mathrm{D})$ ).

\section{Conclusions}

This paper represents a first approach for the characterization of yeast microbiota of Bombino grape variety, with a focus on some technological properties (ethanol, resistance to $\mathrm{SO}_{2}$ and acetic acid), safety issues (biogenic amine production) and enzymatic patterns (pectolytic activity, glucosidase, catalase). This preliminary survey highlights the existence of yeasts with glucosidase activity and a medium pectolytic patterns; in addition, the resistance to ethanol is variable, and only few isolates were able to grow in presence of $15 \%$ ethanol. These isolates were all identified as S. cerevisiae, but in a yeast a decarboxylation activity was found thus suggesting the possibility of recovering amine producing strains from the natural microbiota. A final fermentation trial suggested the existence of an isolate $(S$. cerevisiae 46D) with interesting traits and performances which could be potentially proposed as a starter for Bombino bianco. Further investigations are required for a better characterization of this isolate in terms of secondary compounds produced and fermentative performances in real conditions, as well as typing at strain level and resistance to the common practices of strain storage (e.g., dehydration).

Author Contributions: Conceptualization, A.B., M.S., and M.R.C.; investigation, B.S., D.C., and L.P.; data curation, A.B.; writing—original draft preparation, A.B. and L.P.; writing—review and editing, A.B., M.S., and M.R.C.

Funding: This research received no external funding.

Conflicts of Interest: The authors declare no conflict of interest. 


\section{References}

1. Tufariello, M.; Maiorano, G.; Rampino, P.; Spano, G.; Grieco, F.; Perrotta, C.; Capozzi, V.; Grieco, F. Selection of an autochthonous yeast starter culture for industrial production of Primitivo "Gioia del Colle" PDO/DOC in Apulia (Southern Italy). LWT 2019, 99, 188-196. [CrossRef]

2. Petruzzi, L.; Capozzi, V.; Berbegal, C.; Corbo, M.R.; Bevilacqua, A.; Spano, G.; Sinigaglia, M. Microbial resources and enological significance: Opportunities and benefits. Front. Microbiol. 2017, 8, 995. [CrossRef] [PubMed]

3. Garofalo, C.; Berbegal, C.; Grieco, F.; Tufariello, M.; Spano, G.; Capozzi, V. Selection of indigenous yeast strains for the production of sparkling wines from native Apulian grape varieties. Int. J. Food Microbiol. 2018, 285, 7-17. [CrossRef] [PubMed]

4. Romano, P.; Capece, A. Wine microbiology. In Starter Cultures in Food Production, 1st ed.; Speranza, B., Bevilacqua, A., Corbo, M.R., Sinigaglia, M., Eds.; Wiley Blackwell: Oxford, UK, 2017; pp. 255-282.

5. Ribéreau-Gayon, P.; Denis Dubourdieu, D.; Donèche, B.; Lonvaud, A. Handbook of Enology. In The Microbiology of Wine and Vinifications, 2nd ed.; John Wiley \& Sons: New York, NY, USA, 2006; Volume 1, p. 497.

6. Grieco, F.; Tristezza, M.; Vetrano, C.; Bleve, G.; Panico, E.; Grieco, F.; Mita, G.; Logrieco, A. Exploitation of autochthonous micro-organism potential to enhance the quality of Apulian wine. Ann. Microbiol. 2011, 61, 67-73. [CrossRef]

7. Tristezza, M.; Vetrano, C.; Bleve, G.; Grieco, F.; Tufariello, M.; Quarta, A.; Mita, G.; Spano, G.; Grieco, F. Autochthonous fermentation starters for the industrial production of Negroamaro wines. J. Ind. Microbiol. Biotechnol. 2012, 39, 81-92. [CrossRef] [PubMed]

8. Garofalo, C.; Tristezza, M.; Grieco, F.; Spano, G.; Capozzi, V. From grape berries to wine: Population dynamics of cultivable yeasts associated to "Nero di Troia" autochthonous grape cultivar. World. J. Microbiol. Biotechnol. 2016, 32, 59. [CrossRef] [PubMed]

9. Petruzzi, L.; Bevilacqua, A.; Corbo, M.R.; Speranza, B.; Capozzi, V.; Sinigaglia, M. A focus on quality and safety traits of Saccharomyces cerevisiae isolated from Uva di Troia grape variety. J. Food Sci. 2017, 82, 124-133. [CrossRef]

10. Tristezza, M.; Fantastico, L.; Vetrano, C.; Bleve, G.; Corallo, D.; Grieco, F.; Mita, G.; Grieco, F. Molecular and technological characterization of Saccharomyces cerevisiae strains isolated from natural fermentation of Susumaniello grape must in Apulia, Southern Italy. Int. J. Microbiol. 2014, 897428. [CrossRef]

11. Antonacci, D.; Perniola, R. la vitivinicoltura pugliese. Vigneevini 2005, XXXII, 116-122.

12. Masino, F.; Montevecchi, G.; Arfelli, G.; Antonelli, A. Evaluation of the combined effects of enzymatic treatment and aging on lees on the aroma of wine from Bombino bianco grapes. J. Agric. Food Chem. 2008, 56, 9495-9501. [CrossRef]

13. Baiano, A.; Varva, G.; De Gianni, A.; Terracone, C.; Viggiani, I.; Del Nobile, M.A. Effects of different vinification technologies on physico-chemical properties and antioxidant activity of 'Falanghina' and 'Bombino bianco' wines. Eur. Food Res. Technol. 2013, 237, 831-842. [CrossRef]

14. Vincenzini, M.; Romano, P.; Farris, G.A. Microbiologia del Vino (Wine Microbiology); Casa Editrice Ambrosiana: Milan, Italy, 2006; p. 520.

15. Petruzzi, L.; Bevilacqua, A.; Corbo, M.R.; Garofalo, C.; Baiano, A.; Sinigaglia, M. Selection of autochthonous Saccharomyces cerevisiae strains as wine starters using a polyphasic approach and ochratoxin A removal. J. Food Prot. 2014, 77, 1168-1177. [CrossRef] [PubMed]

16. Barbosa, A.; Lage, P.; Vilela, A.; Mendes-Faia, A.; Mendes-Ferreira, A. Phenotypic and metabolic traits of commercial Saccharomyces cerevisiae yeasts. AMB Express 2014, 4, 39. [CrossRef] [PubMed]

17. Hernández, A.; Martin, A.; Aranda, E.; Pérez-Nevado, F.; Córdoba, M.G. Identification and characterization of yeast isolated from the elaboration of seasoned green table olives. Food Microbiol. 2007, 24, 346-352. [CrossRef]

18. Sinigaglia, M.; Di Benedetto, N.; Bevilacqua, A.; Corbo, M.R.; Capece, A.; Romano, P. Yeasts isolated from olive mill wastewaters from southern Italy: Technological characterization and potential use for phenol removal. Appl. Microbiol. Biotechnol. 2010, 87, 2345-2354. [CrossRef]

19. Bover-Cid, S.; Holzapfel, W.H. Improved screening procedure for biogenic amine production by lactic acid bacteria. Int. J. Food Microbiol. 1999, 53, 33-41. [CrossRef] 
20. Van Gerwen, S.J.C.; Zwietering, M.H. Growth and inactivation models to be used in quantitative risk assessments. J. Food Prot. 1998, 6, 1541-1549. [CrossRef]

21. Baty, F.; Delignette-Muller, M.L. Estimating the bacterial lag time: Which model, which precision? Int. J. Food Microbiol. 2004, 91, 261-277. [CrossRef]

22. Delignette-Muller, M.L.; Cornu, M.; Pouillot, R.; Denis, J.B. Use of the Bayesian modelling in risk assessment: Application to growth of Listeria monocytogenes and food flora in cold-smoked salmon. Int. J. Food Microbiol. 2006, 106, 195-208. [CrossRef]

23. Tristezza, M.; Vetrano, C.; Bleve, G.; Spano, G.; Capozzi, V.; Logrieco, A.; Mita, G.; Grieco, F. Biodiversity and safety aspects of yeast strains characterized from vineyards and spontaneous fermentations in the Apulia Region, Italy. Food Microbiol. 2013, 36, 335-342. [CrossRef]

24. Arevalo-Villena, M.; Briones-Perez, A.; Corbo, M.R.; Sinigaglia, M.; Bevilacqua, A. Biotechnological application of yeasts in food science. Starter cultures, probiotic, and enzyme production. J. Appl. Microbiol. 2017, 123, 1360-1372. [CrossRef] [PubMed]

25. Pando Bedriñana, R.; Querol Simón, A.; Suárez Valles, B. Genetic and phenotypic diversity of autochthonous cider yeasts in a cellar from Asturias. Food Microbiol. 2010, 27, 503-508. [CrossRef] [PubMed]

26. Fia, G.; Giovani, G.; Rosi, I. Study of $\beta$-glucosidase production by wine-related yeasts during alcoholic fermentation. A new rapid fluorimetric method to determine enzymatic activity. J. Appl. Microbiol. 2005, 99, 509-517. [CrossRef] [PubMed]

27. Mateo, J.J.; Di Stefano, R. Description of the beta-glucosidase activity of wine yeast. Food Microbiol. 1997, 14, 583-591. [CrossRef]

28. Chaiyasut, C.; Pengkumsri, N.; Sirilun, S.; Peerajan, S.; Khongtan, S.; Sundaram Sivamaruthi, S. Assessment of changes in the content of anthocyanins, phenolic acids, and antioxidant property of Saccharomyces cerevisiae mediated fermented black rice bran. AMB Express 2017, 7, 114. [CrossRef]

29. Mendes-Ferreira, A.; Mendes-Faia, A.; Leão, C. Survey of hydrogen sulphide production by wine yeasts. J. Food Prot. 2002, 65, 1033-1037. [CrossRef]

30. Bevilacqua, A.; Beneduce, L.; Sinigaglia, M.; Corbo, M.R. Selection of yeasts as starter cultures for table olives. J. Food Sci. 2013, 78, M742-M751. [CrossRef]

31. Merín, M.G.; Martín, M.C.; Rantsiou, K.; Cocolin, L.; de Ambrosini, V.I. Characterization of pectinase activity for enology from yeasts occurring in Argentine Bonarda grape. Braz. J. Microbiol. 2015, 46, 815-823. [CrossRef]

32. Laulund, S.; Wind, A.; Derkx, P.M.F.; Zuliani, V. Regulatory and safety requirements for food cultures. Microorganisms 2017, 5, 28. [CrossRef]

33. Galgano, F.; Caruso, M.; Condelli, N.; Favati, F. Agmatine in fermented foods. Front. Microbiol. 2012, 3, 199. [CrossRef]

(C) 2019 by the authors. Licensee MDPI, Basel, Switzerland. This article is an open access article distributed under the terms and conditions of the Creative Commons Attribution (CC BY) license (http://creativecommons.org/licenses/by/4.0/). 